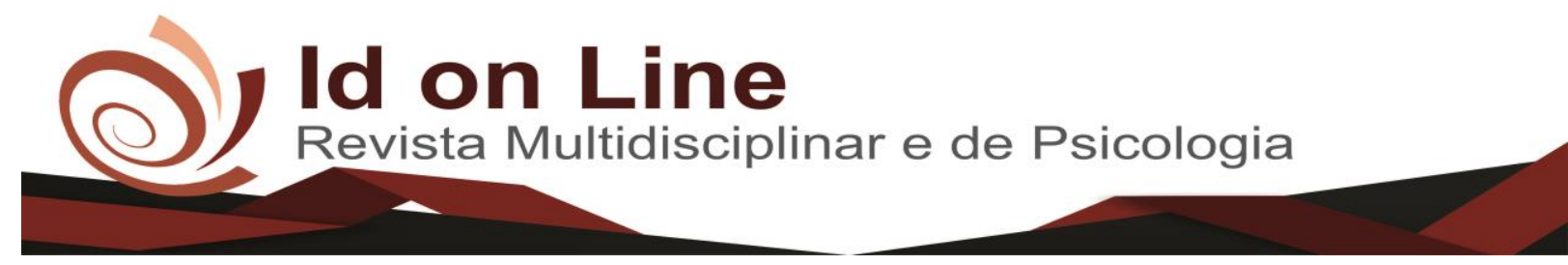

Artigo

\title{
Transparência da Gestão Pública: Um Estudo do Município de Lavras da Mangabeira-Ceará
}

\author{
Francilânio Alves Silva ${ }^{1}$; Antoniel dos Santos Gome Filho ${ }^{2}$
}

\begin{abstract}
Resumo: A transparência na gestão é estimulada pela moderna administração pública ampliando as divulgações das ações governamentais, levando as informações geradas para milhões de brasileiros, contribuindo para uma democracia justa e promovendo um acompanhamento eficaz por parte da população. Desse modo, a presente investigação tem como objetivo geral: Identificar como acontece a transparência e as formas controle da população em relação à gestão pública do município de Lavras da Mangabeira no Estado do Ceará. A abordagem do presente estudo é de ordem quantitativa, descritiva e exploratória. Em seus parâmetros exploratórios a pesquisa utilizou a técnica de amostragem não probabilística, tendo como instrumento de coleta de dados primários um questionário online, disponibilizado na rede mundial de computadores entre os dias 01 a 10 de Outubro de 2018, obtendo um total de 40 questionários respondidos (Amostra: $n=40$ ). Pode-se considerar que o grupo amostral investigado sinaliza que obtém um bom nível de conhecimento acerca das ferramentas utilizadas para o acompanhamento da gestão pública, e que a prefeitura municipal de Lavras da Mangabeira consegue manter por meio dos seus portais eletrônicos informações relevantes sobre as finanças públicas.
\end{abstract}

Palavras-Chaves: Gestão Pública. Portal da Transparência. Lavras da Mangabeira-CE.

\section{Transparency of Public Management: A Study of the Municipality of Lavras da Mangabeira in Ceará}

\begin{abstract}
Transparency in management is stimulated by modern public administration, broadening the dissemination of government actions, bringing the information generated to millions of Brazilians, contributing to a just democracy and promoting effective monitoring by the population. Thus, the present research has the general objective of: Identifying how transparency and control of the population occur in relation to the public management of the municipality of Lavras da Mangabeira in the State of Ceará. The approach of the present study is quantitative, descriptive and exploratory. In its exploratory parameters the research used the non-probabilistic sampling technique, having as an instrument of primary data collection an online questionnaire, made available on the world computer network from October 01 to 10, 2018, obtaining a total of 40 questionnaires answered (Sample: $n=40$ ). It can be considered that the sample group investigated indicates that it obtains a good level of knowledge about the tools used for the monitoring of public management, and that the municipal government of Lavras da Mangabeira manages to maintain through its electronic portals relevant information about the finances public policies.
\end{abstract}

Keywords: Public Management. Transparency Portal. Lavras da Mangabeira-CE.

\footnotetext{
${ }^{1}$ Concludente do curso de Ciências Contábeis da Faculdade Vale do Salgado (FVS).

E-mail: francilanio.alves@hotmail.com

${ }^{2}$ Mestre em Educação pela Universidade Federal do Ceará (UFC). Professor da Faculdade Vale do Salgado (FVS). Coordenador do Laboratório Interdisciplinar em Estudos Organizacionais e do Trabalho (LIEOT-FVS).

Pesquisador do Laboratório Interdisciplinar em Estudos da Violência no Centro Universitário Dr. Leão Sampaio (LIEV-UNILEÃO). E-mail: antonielsantos@fvs.edu.br
}

87 Id on Line Rev. Mult. Psic. V.13, N. 43, p. 87-101, 2019 - ISSN 1981-1179

87 Edição eletrônica em http://idonline.emnuvens.com.br/id 


\section{Introdução}

A transparência na gestão é estimulada pela moderna administração pública ampliando as divulgações das ações governamentais, levando as informações geradas para milhões de brasileiros, contribuindo para uma democracia justa e promovendo um acompanhamento eficaz por parte da população. Desse modo, há um processo de estimulo aos cidadãos para acompanhar as ações públicas municipais, através dos processos de comunicação entre Estado e População.

Na atualidade, o Brasil vive uma crise política, que de modo geral, amplia as ideias de falta de credibilidade da população em relação à administração pública. A transparência na gestão é o caminho para tornar público todos os atos administrativos. O avanço das tecnologias da informação e comunicação (TICs), permite um novo cenário em que os órgãos de controle externo passam avaliar se as administrações estão praticando o Princípio da Publicidade ao divulgarem as informações públicas.

Em estudos realizados na microrregião do sudeste de Goiás, Bernardino (2016) aponta que nos municípios de maior nível socioeconômico, existe uma maior observância ao Princípio da Transparência. Damacena, Soares e Silva (2016) apontam que as regras trazidas pela Lei de Responsabilidade Fiscal, permitem um melhor acompanhamento dos recursos públicos, e os chefes executivos não poderão descumprir sobe pena de sofrer sanções administrativas.

Diante do exposto e entendendo que a publicidade pública deve ser fomentada em todos os municípios do país, em especial no município de Lavras da Mangabeira, no Estado do Ceará, levanta-se os seguintes questionamentos: A transparência da gestão pública está sendo efetivada em observância ao cumprimento as leis federais de contas públicas e de responsabilidade fiscal? A população universitária do município de Lavras da Mangabeira-CE acompanha a gestão pública?

Diante da presente indagação, a investigação tem como objetivo geral: Identificar como acontece a transparência e as formas controle da população em relação a gestão pública do município de Lavras da Mangabeira-CE. Como objetivos específicos têm-se: analisar as formas de divulgação acerca da execução orçamentaria e financeira realizadas pelo município estudado; discutir sobre a importância da transparência municipal para a participação popular no controle social; e, transcrever os dados adquiridos através das análises dos portais eletrônicos da prefeitura municipal de Lavras da Mangabeira-CE.

Destaca-se que, a lei complementar 131 de 27 de maio de 2009, Lei da Transparência, alterou a redação da Lei de Responsabilidade Fiscal, disponibilizando em tempo real 
informações no que diz respeito a execução orçamentaria e financeira, a observância por parte do município. O município de Lavras da Mangabeira, situado na Região Centro-Sul do Ceará, possui 31.584 habitantes, onde a maior parte da população é residente na zona rural, em localidades onde pode haver uma maior dificuldade na divulgação das informações públicas, o que pode comprometer o controle social (IBGE, 2010).

Por isso, a investigação se justifica pelo fato que o acesso as informações produzidas pelo Estado constitui-se em um fundamento da democracia, permitindo aos indivíduos participarem do processo de tomada de decisões. O atual estado da política brasileira permite que os cidadãos exijam cada vez mais dos seus governantes, logo, o acompanhamento da transparência de informações permite a comunidade fiscalizar todas as esferas administrativas, acompanhando como está sendo investido os recursos públicos. Desta forma verificar se o município estudado está cumprindo o que determina a Lei da Transparência, é relevante na tentativa de fortalecer o controle social visando uma sociedade mais justa e participativa no processo de administração pública do município.

\section{Contabilidade Pública}

A contabilidade ganhou força no Brasil ainda no período colonial, surgindo da necessidade de controle contábil para o desenvolvimento das primeiras alfandegas. $\mathrm{O}$ desenvolvimento da colônia resultou na necessidade do profissional contábil, inicialmente denominado como Contador Geral e Guarda Livros (REIS; DA SILVA, 2008).

$\mathrm{Na}$ atualidade, a Contabilidade Pública é o ramo da contabilidade responsável pelo controle, registro, demonstração e execução do orçamento público. Ela está interessada também em todos os atos praticados pelo administrador, sejam de natureza orçamentária (previsão da receita, fixação da despesa, empenho.), ou seja, meramente administrativos (contratos, convênios, acordos) representativos de valores potenciais que poderão afetar o patrimônio no futuro. A Norma Brasileira de Contabilidade Aplicada ao Setor Público - NBC T 16.1 (2012), define com clareza o objetivo da Contabilidade Pública,

O objetivo da Contabilidade aplicada ao Setor Público é fornecer aos usuários informações sobre os resultados alcançados e os aspectos de natureza orçamentária, econômica, financeira e física do patrimônio da entidade do setor público e suas mutações, em apoio ao processo de tomada de decisão; a adequada prestação de contas; e o necessário suporte para a instrumentalização do controle social (CONSELHO FEDERAL DE CONTABILIDADE, 2012, p. 8). 
O objeto de estudo da contabilidade pública é o patrimônio público, tendo como campo de atuação todas as entidades do setor público. Felgueiras (2014) define o patrimônio público como sendo aquele de uso comum do povo, observando o uso direto por parte da sociedade e dos indivíduos, após definido como patrimônio público, deve-se registrar os lançamentos na contabilidade.

A contabilidade pública exerce importante fator social, através de seus registros e demonstrações produzidas com o intuito de promover a população o acompanhamento de todos os atos e fatos que afetam o patrimônio público, a contabilidade pública serve como fonte de informações para todos os usuários sendo eles internos ou externos, possibilita também, uma comparação nas análises das informações contábeis nos diferentes níveis de governo e auxilia no desempenho da gestão (MARQUES, 2015).

A contabilidade pública atua como instrumento de suporte, proporcionando aos gestores informações fidedignas e completas que são de fundamental importância para a tomada de decisão. Dentro da Teoria Orçamentaria, Bueno (2012), ressalta a necessidade de observância das peças orçamentarias estabelecidas na Constituição Federal do Brasil, de 1988, que compõem o planejamento das ações públicas em períodos de médio e curto prazo. Essas peças são o Plano Plurianual de Investimento (PPA), a Lei de Diretrizes Orçamentarias (LDO), e a Lei Orçamentaria Anual (LOA).

As peças que compõem o orçamento são de extrema importância para a sociedade em geral que irá evidenciar a prioridade de gastos, as diretrizes dos investimentos por parte dos gestores públicos, compondo assim o orçamento público que será observado pela contabilidade pública em todos os atos e fatos praticados pela administração, possibilitando assim a transparência na gestão pública.

\section{Transparência na Gestão Pública}

Ao debater a transparência pública é importante ressaltar que seu início se dá quando informação de interesse público chegam de forma clara para quem é de direito. A Lei Complementar 131 de 27 de maio de 2009, a Lei da Transparência, alterou a redação da Lei de Responsabilidade Fiscal, visando o incentivo a participação popular, como como a disponibilização das informações no que diz respeito à execução orçamentaria e financeira de todas as esferas: União, Estados, Distrito Federal e Municípios; informa ainda sobre quais os dados devem ser divulgados na internet; quanto às despesas no momento de sua realização, 
devem informar o número do referido processo, os beneficiários do pagamento, e sempre que for o caso, informar o processo licitatório que correspondente. Quanto à receita deve dar transparência a todo o recebimento de recursos das unidades gestoras até mesmos aos recursos extraordinários (BRASIL, 2017).

A Controladoria Geral da União por meio de seu manual da Lei de Acesso a Informação para Estados e Municípios publicado no ano de 2013, ressalta que é direito fundamental humano o acesso a informação (CGU, 2013). Destaca-se que a Constituição Federal de 1988, Título II, Capítulo I, Artigo $5^{\circ}$, inciso XXXIII, diz que o acesso a informações públicas é um direito fundamental garantido a todos os cidadãos. Por tanto, todos tem o direito de receber por parte dos órgãos públicos informações tanto de interesse particular como de interesse público, devendo observar os prazos previstos, sob pena de responsabilidade se assim negar a da qualquer informação, ressalvando apenas aquelas que o sigilo seja imprescindível à segurança da sociedade. Sendo assim a informação produzida, guardada, organizada e gerenciada pelos órgãos públicos são consideradas um bem público (BRASIL, 2017).

A Lei de Acesso a Informação 12.527/2011, regulamenta o direito constitucional de acesso à informação criando mecanismos de divulgação inerentes as atividades dos órgãos e entidades públicas, devendo a lei ser cumprida por todos os órgãos e entidades da administração direta e indireta. O Capítulo II, Art. $6^{\circ}$ diz que os órgãos e entidades são os responsáveis pela observância pelas normas que assegurem uma gestão transparente, onde o amplo acesso seja mantido, protegendo a informação para que, sempre que necessário esteja disponibilizada de forma integra e autentica; quanto ao extravio de informações, a lei deixa bem claro que o interessado terá o direito de requerer uma sindicância para apurar a perda dos documentos solicitados, devendo o responsável pela guarda da informação deve cumprir um prazo de 10 dias para justificar o fato (BRASIL, 2017).

\footnotetext{
Art. $6^{\circ}$ Cabe aos órgãos e entidades do poder público, observadas as normas e procedimentos específicos aplicáveis, assegurar a:

I - gestão transparente da informação, propiciando amplo acesso a ela e sua divulgação;

II - proteção da informação, garantindo-se sua disponibilidade, autenticidade e integridade; e,

III - proteção da informação sigilosa e da informação pessoal, observada a sua disponibilidade, autenticidade, integridade e eventual restrição de acesso.
}

A transparência na gestão pública permite a população o acompanhamento dos atos praticados pelos gestores e assim proporciona um controle eficaz, desenvolvendo as noções de cidadania. A Lei de Responsabilidade Fiscal (Lei Complementar No 101, DE 4 DE MAIO DE 
2000) estabelece as normas de finanças públicas voltadas para a responsabilidade na gestão fiscal, também compõe os dispositivos legais que obrigam a divulgação das informações por parte das entidades públicas; logo, esses dispositivos legais se constituem como um importante passo na busca da recuperação do equilíbrio das contas públicas reforçando a ligação direta do planejamento e a execução dos gastos, visando sempre também manter a participação da sociedade (BRASIL, 2017).

Menezes et al. (2013) reforça o pensamento de que o mecanismo composto pelas: (01) Lei da Transparência, (02) Lei de Responsabilidade Fiscal, e, (03) Lei de Acesso a Informação, constitui importantes prerrogativas na busca e consolidação do respeito a cidadania.

O Brasil tem dado um importante passo visando alcançar níveis satisfatórios da transparência pública, os mecanismos citados de obtenção de informações, estabelecem o conceito que o acesso é regra geral, e um importante meio para aumentar a confiabilidade nos atos governamentais, assim, a administração pública está sujeita a atender sempre que solicitada as demandas dos cidadãos em observância as leis que regulamentam o controle social por meio do acompanhamento das ações desenvolvidas.

\section{O Portal da Transparência}

Portal da Transparência do Governo Federal é um convite para todo cidadão exercer seu papel de fiscalizador dos órgãos públicos. No âmbito local destaca-se que as prefeituras devem informar a população de forma clara e completa sobre os gastos dos recursos públicos. A Lei de Responsabilidade Fiscal nos art. 48-A e 49, diz que os cidadãos devem participar da tomada de decisão em relação à aplicação do dinheiro público, ressalta também que o cidadão é o principal interessado, por isso deve ser o centro de todos os atos praticados pela administração (BRASIL, 2017).

\footnotetext{
Art. 48-A. Para os fins a que se refere o inciso II do parágrafo único do art. 48, os entes da Federação disponibilizarão a qualquer pessoa física ou jurídica o acesso a informações.

I - quanto à despesa: todos os atos praticados pelas unidades gestoras no decorrer da execução da despesa, no momento de sua realização, com a disponibilização mínima dos dados referentes ao número do correspondente processo, ao bem fornecido ou ao serviço prestado, à pessoa física ou jurídica beneficiária do pagamento e, quando for o caso, ao procedimento licitatório realizado;

II - quanto à receita: o lançamento e o recebimento de toda a receita das unidades gestoras, inclusive referente a recursos extraordinários.
} 
Art. 49. As contas apresentadas pelo Chefe do Poder Executivo ficarão disponíveis, durante todo o exercício, no respectivo Poder Legislativo e no órgão técnico responsável pela sua elaboração, para consulta e apreciação pelos cidadãos e instituições da sociedade.

Giovani (2013) ressalta que o dinheiro público não pertence aos agentes políticos, não sendo possível a confusão patrimonial usando o dinheiro público em seu benefício próprio, também ressalta que a transparência tem como objetivo principal evitar o desvio de recursos, promovendo a fiscalização. Nunes (2011) destaca que a administração pública deve atuar com honestidade e presteza, honrando aqueles que pagam seus impostos, contribuições e outras formas de receitas públicas, representados pelos governantes, que devem prestar toda a assistência necessária para a satisfação popular.

O Portal da Transparência fornece informações fiscais (receitas e despesas), tais como os salários, cargos e lotação dos servidores, bem como outras informações também de interesse popular, tais como diárias pagas aos servidores, convênios firmados e despesas especificam. Ribeiro e Marcos (2014), afirmam que o portal é fonte de informações, mas, as informações para possibilitar o controle social devem ser compreendidas pelos cidadãos, para que estes possam efetivar seu papel de fiscalizador.

Portanto, a administração pública precisa se adequar a realidade atual em relação às Tecnologias da Informação e Comunicação (TIC), a internet e as redes de computadores, criam melhores condições para a transmissão de informações rápidas e de grande alcance. Para Gomes (2012) que embora reconhecendo o poder das novas TICs, para a realização da transparência publica, o fortalecimento da democracia e das políticas públicas responsáveis, ainda são o caminho mais eficaz para informações de qualidade. Assim, o Portal da Transparência consegue disponibilizar as informações necessárias à população, mas, o conteúdo que é exposto e declarado no portal precisa conter a realidade, evidenciando o comprometimento dos gestores públicos para com a sociedade.

\section{Metodologia}

A investigação caracteriza-se como um estudo de natureza básica, que foi aplicado junto à população votante e universitária do município de Lavras da Mangabeira no Estado do Ceará, que de acordo Instituto Brasileiro de Geografia e Estatística (IBGE, 2010) possui uma população de aproximadamente 31.584 mil habitantes. 
A abordagem do presente estudo é de ordem quantitativa, descritiva e exploratória (GIL, 2009). Em seus parâmetros exploratórios a pesquisa utilizou a técnica de amostragem não probabilística, tendo como instrumento de coleta de dados primários um questionário online, disponibilizado na rede mundial de computadores entre os dias 01 a 10 de Outubro de 2018, obtendo um total de 40 questionários respondidos (Amostra: $n=40$ ).

A investigação foi utilizada para conhecer como está se concretizando a transparência na administração pública, sempre em observância nos dispositivos da Lei de Acesso a Informação ( $n^{\circ}$ 12.527/2011). Participaram da pesquisa os cidadãos lavrenses, residentes na zona urbana do município que tinham entre 18 e 70 anos de idade, que estavam devidamente matriculados em uma Instituição de Ensino Superior, não participaram da pesquisa aqueles que não residiam no município em estudo, eram analfabetos, tinham menos de 18 anos e maiores que 70 anos. Durante a coleta de dados online foram apresentados os seguintes termos: Termo de Consentimento Livre e Esclarecido - TCLE e Termo de Consentimento Pós-Esclarecido, tais termos estão em consonância com a Resolução N ${ }^{\circ}$ 510, do Conselho Nacional de Saúde. Após o período de coleta de dados, as respostas obtidas foram analisadas através de estatística descritiva, com utilização do Microsoft Excel 2010, sendo os resultados apresentados a seguir.

\section{Resultados e Discussões}

A tabela 01 apresenta a descrição do perfil sociodemográfico da amostra estudada segundo: o gênero, renda mensal, faixa etária, estado civil e curso de nível superior.

Tabela 01: Perfil Demográfico

\begin{tabular}{c|c}
\hline Perfil demográfico da amostra & Amostra $\mathbf{n}=\mathbf{4 0}$ \\
\hline Gênero & $\mathbf{\%}$ \\
\hline Masculino & 36,8 \\
\hline Feminino & 63,2 \\
\hline Outro & 0 \\
\hline Renda Mensal & $\mathbf{2 6 , 3}$ \\
\hline Menos de 1 Salário mínimo & 57,9 \\
\hline Entre 1 e 2 Salários Mínimos & 15,8 \\
\hline Entre 3 e 4 Salários Mínimos & \\
\hline & \\
\hline
\end{tabular}




\begin{tabular}{|c|c|}
\hline Faixa Etária & $\%$ \\
\hline 18 a 25 & 73,7 \\
\hline 25 a 35 & 26,3 \\
\hline 35 a 60 & 0 \\
\hline Mais de 60 & 0 \\
\hline Estado Civil & $\%$ \\
\hline Casado & 5,3 \\
\hline Solteiro & 94,7 \\
\hline Viúvo & 0 \\
\hline Divorciado & 0 \\
\hline Outro & 0 \\
\hline Curso & $\%$ \\
\hline Administração & 15,8 \\
\hline Ciências Contábeis & 5,3 \\
\hline Serviço Social & 15,8 \\
\hline Direito & 10,5 \\
\hline Enfermagem & 26,3 \\
\hline Fisioterapia & 15,8 \\
\hline Analises de Sistemas & 0 \\
\hline Psicologia & 5,3 \\
\hline Outro & 5,3 \\
\hline
\end{tabular}

Fonte: Dados da pesquisa (2018)

Como pode ser observado o perfil que sobressai é constituído por pessoas do gênero feminino (63,2\%), com renda mensal de 01 a 02 salários mínimos (57,9\%), com faixa etária de 18 a 25 anos $(73,7 \%)$, solteiros/as $(94,7 \%)$ e cursando o ensino superior com destaque para os cursos de Enfermagem (26,3\%), Fisioterapia e Serviço Social (15,8\%). Aponta-se que a concentração de pessoas com renda mensal entre 1 e 2 salários mínimos, se dá pelo fato da proporção de trabalhadores formais em relação a população total é apenas 6,8\%.

Em 2016, o salário médio mensal era de 1.8 salários mínimos. A proporção de pessoas ocupadas em relação à população total era de $6.8 \%$. Na comparação com os outros municípios do estado, ocupava as posições 21 de 184 e 114 de 184, respectivamente. Já na comparação com cidades do país todo, ficava na posição 2836 de 5570 e 4247 de 5570, respectivamente. Considerando domicílios com rendimentos mensais de até meio salário mínimo por pessoa, tinha $56.1 \%$ da população nessas condições, o que o colocava na posição 50 de 184 dentre as cidades do estado e na posição 317 de 5570 dentre as cidades do Brasil (IBGE, 2016). 
Diante desta questão observa-se que em sua totalidade os pesquisados estão matriculados em cursos de ensino superior, o que reflete a tendência da busca crescente por profissionalização a fim de adentrar no mercado de trabalho, o número de estudantes de nível superior em 2015 alcançou um quantitativo de oito milhões de estudantes (MEC, 2016). Outra característica da amostra que merece destaque é a relação entre gênero e curso, ou seja, o gênero feminino compõe 63,2\%, e os cursos de Enfermagem (26,3\%) e Fisioterapia (15,8\%) se sobressaem, indo de encontro ao debate apresentado por Matos, Toassi e Oliveira (2013) quando apontam que há uma feminização das profissões na área da saúde no Brasil, desse modo, há uma grande possibilidade da correlação gênero feminino-curso de saúde na amostra.

Como disse Menezes et al. (2013), as leis que contribuem para a transparência pública devem ser acompanhadas e efetivadas através da observância e participação da população que deve estar atenta as formas e meios de divulgação dos recursos públicos.

A tabela 02 apresenta como acontece o acompanhamento das finanças públicas do município de Lavras da Mangabeira, bem como sobre o Portal da Transparência.

Tabela 02: Acompanhamento Finanças Públicas

\begin{tabular}{|c|c|}
\hline Grau de importância das Finanças Públicas & $\underset{\%}{\operatorname{Amostra} \mathrm{n}=40}$ \\
\hline Muito Pouco & 5,3 \\
\hline Pouco & 5,3 \\
\hline Médio & 21,1 \\
\hline Alto & 36,8 \\
\hline Muito Alto & 31,6 \\
\hline Conhece o Portal da Transparência & $\%$ \\
\hline Sim & 68,4 \\
\hline Não & 31,6 \\
\hline Prefiro não comentar & 0 \\
\hline $\begin{array}{c}\text { Frequência que solicita informações a Prefeitura } \\
\text { Municipal }\end{array}$ & $\%$ \\
\hline Uma Única vez & 0 \\
\hline Frequentemente & 0 \\
\hline Raramente & 42,1 \\
\hline Nunca & 57,9 \\
\hline Acessa o Portal da Transparência & $\%$ \\
\hline Sim & 52,6 \\
\hline Não & 47,4 \\
\hline Talvez & 0 \\
\hline
\end{tabular}




\begin{tabular}{|c|c|}
\hline $\begin{array}{c}\text { Realiza acompanhamento da Gestão Pública } \\
\text { Municipal através de (?) }\end{array}$ & $\%$ \\
\hline Sessões da Câmara Municipal & 10,5 \\
\hline Internet e Rede Sociais & 21,1 \\
\hline Portal da Transparência & 26,3 \\
\hline Outro & 42,1 \\
\hline $\begin{array}{l}\text { São mecanismos de publicidades utilizados pela } \\
\text { prefeitura para divulgação dos gastos públicos } \\
(?)\end{array}$ & $\%$ \\
\hline Outdoor & 0 \\
\hline Prestações de contas com a comunidade & 0 \\
\hline Divulgações em redes sociais & 21,1 \\
\hline Portal da Transparência & 36,8 \\
\hline Outro & 42,1 \\
\hline $\begin{array}{c}\text { Os mecanismos de publicidade para divulgação } \\
\text { dos gastos públicos municipais satisfazem os } \\
\text { anseios da população no âmbito da informação } \\
\text { (?) }\end{array}$ & $\%$ \\
\hline Muito Pouco & 47,4 \\
\hline Pouco & 31,6 \\
\hline Médio & 21,1 \\
\hline Alto & 0 \\
\hline Muito alto & 0 \\
\hline $\begin{array}{c}\text { Conhece alguma das Leis de promoção a } \\
\text { Transparência (?) }\end{array}$ & $\%$ \\
\hline Lei complementar 131/2009 (Lei da Transparência) & 66,7 \\
\hline Lei 12.527 (Lei de acesso a informação) & 16,7 \\
\hline $\begin{array}{l}\text { Lei complementar 101/2000 (Lei de } \\
\text { responsabilidade Fiscal) }\end{array}$ & 72,2 \\
\hline $\begin{array}{c}\text { A gestão municipal promove a participação da } \\
\text { população na gestão (?) }\end{array}$ & $\%$ \\
\hline Sim & 0 \\
\hline Não & 84,2 \\
\hline Prefiro não responder & 15,8 \\
\hline
\end{tabular}

Fonte: Dados da Pesquisa (2018)

Como é visualizado na tabela 02 o grau de importância do entendimento sobre finanças públicas é considerado em sua maioria de alto a muito alto. Como foi ressaltado por Marques (2015) o acompanhamento dos registros contábeis possibilita uma melhor gestão dos recursos públicos potencializando os resultados dos gestores.

Neste sentido chama a atenção que $68,4 \%$ dos pesquisados conhecem a ferramenta de controle que é o Portal da Transparência, porém percebe-se que a maioria dos pesquisados, 
cerca de 57,9\% nunca solicitaram nenhuma informação ou esclarecimento sobre os registros evidenciados pela prefeitura municipal.

No que tange o acesso ao Portal da Transparência, destaca-se que 52,6\% confirmaram que já utilizaram essa ferramenta, mas, 47,4 \% dos respondentes informam que nunca utilizaram; esse quantitativo é importante, pois mesmo conhecendo a ferramenta não há uma utilização efetiva da mesma. Desse modo, o cidadão não exerce seu papel de agente fiscalizador. Outro dado interessante diz respeito ao acompanhamento da gestão pública municipal, pois o número de respondentes que acompanham as sessões da câmara municipal é baixo $(10,5 \%)$.

Os mecanismos utilizados pela prefeitura para prestação de contas com a sociedade indicam que não estão suprindo os anseios da população. Desta forma conforme a Lei Complementar 131 de 27 de maio de 2009 (Lei da Transparência) é imprescindível que a informação seja disponibilizada de forma clara, afim de atingir toda a população contribuindo para o controle social.

Os percentuais de conhecimento sobre a Lei complementar 101/2000 (Lei de Responsabilidade Fiscal) atingiram 72,2\% o que é bastante relevante, de acordo Bernardino (2016) essa lei vem ao encontro dos anseios da sociedade brasileira, que sempre clamou por administrações transparentes, voltadas apenas para atender as necessidades dos cidadãos, por fim a pesquisa evidenciou que a grande maioria dos investigados cerca de $84,2 \%$ revelam que a prefeitura do município de Lavras da Mangabeira não promove a participação popular, não contribuindo para uma gestão participativa.

\section{Considerações Finais}

Diante dos procedimentos técnicos-metodológicos traçados para a investigação pode-se considerar que o grupo amostral investigado sinaliza que obtém um bom nível de conhecimento acerca das ferramentas utilizadas para o acompanhamento da gestão pública, e que a prefeitura municipal de Lavras da Mangabeira consegue manter por meio dos seus portais eletrônicos informações relevantes sobre as finanças públicas, há indicativos que uma parcela alta da amostra não solicita informações a Prefeitura Municipal de Lavras da Mangabeira, sendo este representa uma possível falta de comunicação entre gestores e cidadãos.

Frente a este último indicativo, aponta-se a necessidade de investigações que ampliem o grupo amostral, a fim de reconhecer os pormenores das relações dos gestores municipais e a 
falta de solicitações de informações a respeito da governança. Assim, acredita-se que as pesquisas de abordagem quanti-qualitativas podem ser delineadas para tal fim, aumentando assim o escopo analítico do tema proposto neste estudo no Município de Lavras da Mangabeira.

Outro ponto de destaque em relação ao grupo amostral refere-se ao conhecimento das leis que amparam o cidadão em busca de efetivar o controle social. A busca de informações no portal da transparência nos aponta que de forma indireta os cidadãos lavrenses (universitários) estão buscando exercer o seu papel, porém como foi demostrado a administração pública do município necessita incentivar a participação popular para que assim tenha uma relação mais transparente com a população.

\section{Referências}

BERNADINO, G. C. DOS S. A transparência na gestão pública: estudo comparado de sua concretização nos municípios da microrregião do sudoeste de Goiás. Goiás, 2016. Disponível em: <https://repositorio.bc.ufg.br/bitstream/ri/11229/1/TCCG\%20\%E2\%80\% 93\%20Ci\%C3\%AAncias\%20Cont\%C3\%A1beis\%20\%E2\%80\%93\%20Geraldo\%20Cicari\%2 0Bernardino\%20dos\%20Santos.pd>. Acesso em 09 set. 2017

BRASIL. Constituição da república federativa do Brasil, de 1988. Assegura o exercício dos direitos sociais e individuais. Disponível em: $<$ http://www.planalto.gov.br/ ccivil_03/constituicao/constituicao.htm>. Acesso em: 15 out. 2017.

BRASIL. Lei complementar n. 101, de 04 de maio de 2000. Estabelece normas de finanças públicas voltadas para a responsabilidade na gestão fiscal e dá outras providências. Disponível em:< http://www.planalto.gov.br/ccivil_03/leis/LCP/Lcp101.htm>. Acesso em: 13 out. 2017.

BRASIL. Lei complementar n. 131, de 27 de maio de 2009. ACRESCENTA DISPOSITIVOS À COMPLEMENTAR $\mathrm{N}^{\circ}$ 101. Disponível em: <http://www.planalto.gov.br /ccivil_03/leis/lcp/lcp131.htm>. Acesso em: 15 out. 2017.

BRASIL. Lei n. 12.527, de 18 de novembro de 2008. Regula o acesso a informações. Disponível em:< http://www.planalto.gov.br/ccivil_03/_ato2011-2014/2011/lei/l12527.htm>. Acesso em: 13 out. 2017.

BUENO, A. S. A contabilidade pública e o impacto da lei de responsabilidade fiscal na administração pública. $\quad$ Goiânia, 2012. Disponível em: $\leq$ https://monografias.ufrn.br/jspui/bitstream/123456789/1929/3/A\%20influ\%C3\%AAncia\%2 0da\%20contabilidade_Monografia_Silva.pdf $>$. Acesso em 10 out. 2017

CONSELHO FEDERAL DE CONTABILIDAE (CFC), Contabilidade aplicada ao setor público. Brasília, 2012. Disponível em: <http://portalcfc.org.br/wordpress/wpcontent/uploads/2013/01/Setor_P\%C3\%BAblico.pdf>. Acesso em 08 set. 2017 
CONTROLADORIA GERAL DA UNIÃO (CGU), Manual da lei de acesso a informação para estados e municípios. Brasília, 2013. Disponível em: <http://www.cgu.gov.br/ Publicacoes/transparencia-publica/brasil transparente/arquivos/manual_lai_estadosmunicipios .pdf> . Acesso em 08 set. 2017

CONTROLADORIA GERAL DA UNIÃO (CGU), Portal da transparência. Brasília, 2017. Disponível em: <http://www.portaldatransparencia.gov.br/sobre/>. Acesso em 08 out. 2017

DAMACENA, F. S. C; SOARES, K. S; SILVA, I. R. A lei de responsabilidade fiscal e o princípio da transparência. São Paulo, 2016. Disponível em: <http://nippromove.hospedagemdesites.ws/anais_simposio/arquivos_up/documentos/artigos/5 f9c319ef7e5f54b8e8f12c86d500015.pdf>. Acesso em 09 set. 2017

FELGUEIRAS, J. A. Contabilidade pública. Teoria e 420 questões de concursos com gabarito. São Paulo: Método, 2015, p 11 - 24

GIL, A. C. Métodos e técnicas de pesquisa social. 6. ed. São Paulo: Atlas, 2009.

GIOVANI, R. Y. DE SÁ. A importância do portal da transparência na administração pública. Pato Branco, 2013. Disponível em: <http://repositorio.roca.utfpr. edu.br/jspui/bitstream/1/5784/1/PB_GP_1l1_2014_10.pdf>. Acesso em 12 out. 2017

GOMES, J. A. P. Estado, sociedade e interações digitais: expectativas democráticas. Salvador, 2012. Disponível em: <http://www.repositorio.ufba.br:8080 /ri/bitstream/ri/16738/3/estado,\%20sociedade\%20e\%20interacoes.pdf\#page=16>. Acesso em 12 out. 2017

INSTITUTO BRASILEIRO DE GEOGRAFIA E ESTATÍSTICA (IBGE). Censo demográfico. 2010. Disponível em:< https://cidades.ibge.gov.br/brasil/ce/lavras-damangabeira/panorama>. Acesso em 14 set. 2018

MARQUES, J. S. A influência da contabilidade aplicada ao setor público no controle dos gastos públicos: um estudo de caso no município de Serra Negra do Norte/RN. Caicó/RN, 2015.

Disponível

em: <https://monografias.ufrn.br/jspui/bitstream/123456789/1929/3/A\%20influ\%C3\%AAncia\%2 0da\%20contabilidade_Monografia_Silva.pdf>.Acesso em 10 out. 2017

MATOS, I. B.; TOASSI, R. F. C.; OLIVEIRA, M. C. Health Professions and Occupations and Feminization Process: Trends and Implications. Athenea Digital, v.13, n. 2, 2013.

MENEZES, A. P. et al. Transparência na gestão pública municipal: um estudo dos municípios de Santa Maria e Novo Hamburgo/RS. Santa Crus do Sul, 2013. Disponível em: < https://online.unisc.br/seer/index.php/cepe/article/viewFile/3439/3124>. Acesso em 12 out. 2017

NUNES, J. Observatório social: Contribuição para a transparência na gestão pública. Florianópolis, 2011. Disponível em: <http://tcc.bu.ufsc.br/Contabeis304503.pdf>. Acesso em 12 out. 2017 
REIS, A. J; SILVA, L. S. A história da contabilidade. 2008. Disponível em:<http://www.revistas.unifacs.br/index.php/sepa/article/view/299/247>. Acesso em 12 out. 2017

RIBEIRO, F. F; MARCOS, C. B. Como o cidadão avalia o portal? Um estudo com os usuários do portal da transparência do Governo Federal. Brasília 2014. Disponível em: < https://ojs.cgu.gov.br/index.php/Revista_da_CGU/article/view/16/pdf_17>. Acesso em 12 out. 2017

Como citar este artigo (Formato ABNT):

SILVA, Francilânio Alves; GOMES FILHO, Antoniel dos Santos. Transparência da Gestão Pública: Um Estudo do Município de Lavras da Mangabeira-Ceará. Id on Line Rev.Mult. Psic., 2019, vol.13, n.43, p. 87-101. ISSN: 1981-1179.

Recebido: 17/11/2018;

Aceito: 19/11/2018 